\title{
Risk factors for Plasmodium falciparum hyperparasitaemia in malarious children
}

\author{
Akintunde Sowunmi*, Titilope M Okuboyejo, Grace O Gbotosho and Christian T Happi
}

\begin{abstract}
Background: Hyperparasitaemia is a feature of childhood severe malaria but there is little information on the risk factors for hyperparasitaemia in malarious children

Methods: The risk factors associated with Plasmodium falciparum hyperparasitaemia, defined as asexual parasitaemia $>250,000 / \mu \mathrm{l}$, at presentation were evaluated in 3338 malarious children enrolled prospectively between 2008 and 2010 in an endemic area of southwestern Nigeria.

Results: At enrolment, 97 (3\%) of 3338 malarious children had hyperparasitaemia. In a multiple regression model, 3 factors were found to be independent risk factors for the presence of hyperparasitaemia at enrolment: an age $\leq 11$ years (Adjusted odds ratio $[A O R]=2.85,95 \%$ confidence interval $[\mathrm{Cl}] 1.23-6.61, \mathrm{P}=0.014$ ), fever $(\mathrm{AOR}=2.02,95 \%$ $\mathrm{Cl} 1.23-3.29, \mathrm{P}=0.005)$, and enrolment after year 2008 ( $\mathrm{AOR}=0.42,95 \% \mathrm{Cl} 0.24-0.73, \mathrm{P}=0.002)$. Duration of illness $\leq 3 \mathrm{~d}$ was associated with increased risk of hyperparasitaemia. There was no association between season and hyperparasitaemia. Compared to non-hyperparasitaemia, hyperparasitaemia was associated with an increased risk of progression to cerebral malaria $(P<0.0001)$. The risk of progression in hyperparasitaemic children was higher in $<$ 5-year olds $(P=0.02)$.
\end{abstract}

Conclusion: Young age and presence of fever are independent risk factors for hyperparasitaemia which is associated with an increased risk of progression to cerebral malaria. The findings have implications for case and community management of childhood hyperparasitaemia and for malaria control efforts in sub-Saharan Africa where severe malaria is relatively common.

Keywords: Hyperparasitaemia, children, risk factors, Nigeria

\section{Background}

Plasmodium falciparum hyperparasitaemia, defined as $>$ 250,000 asexual parasites $/ \mu$ l blood or $>4 \%$ parasitized erythrocytes $[1,2]$, is a feature of severe childhood malaria, is indicative of a large sequestered parasite biomass, and poses a risk for recrudescent infections following antimalarial drug treatment $[3,4]$. Hyperparasitaemia is relatively more frequent in the relatively non-immune individuals [1] but may also occur in semi-immune populations with much variability in clinical features [5]. However, in some non-endemic populations, for example in Indian children, it is associated with increased risk of mortality [6].

\footnotetext{
* Correspondence: akinsowunmi@hotmail.com

Department of Pharmacology \& Therapeutics and Institute for Medical Research and Training, University of Ibadan, Ibadan, Nigeria
}

Delay in parasite clearance by all antimalarial drugs is associated with increasing parasitaemia and hyperparasitaemia $[4,7]$ and is thought to be contributory to drug treatment failure in P. falciparum to antimalarials including artemisinin derivatives and artemisinin-based combinations [8]. A recent study from Thailand [9], an area of lesser intensity of malaria transmission than Nigeria [10], has shown that hyperparasitaemia is a risk factor for gametocyte carriage. Although hyperparasitaemia is frequently reported in many antimalarial and malaria studies there is little or no information on the risk factors for hyperparasitaemia in childhood falciparum infections. Such information is necessary as it may potentially harness the efforts aimed at the management and control of drug resistance in both the individual and the community. In the present study we evaluated the factors that influence the occurrence of hyperparasitaemia in children

\section{() Biomed Central}


presenting with acute, symptomatic, uncomplicated, $P$. falciparum malaria in a hyperendemic area of malaria in southwest Nigeria and describe the risk of hyperparasitaemia in these children.

\section{Methods}

\section{Patients}

The study was carried out between January 2008 and December 2010 in patients presenting at the Malaria Clinic at the University College Hospital in Ibadan, an endemic area for malaria in southwestern Nigeria [10]. In this area, transmission occurs all year round but is more intense during the rainy season from April to October. P. falciparum is the predominant species accounting for $99 \%$ of all infections. Children are more affected than adults, and apparently asymptomatic infections occur in older school children and adults.

During the study period, all children with febrile illnesses suspected to be or clinically diagnosed as acute falciparum malaria were enrolled in the study after obtaining a written informed consent from parents or guardian of the children. Clinical evaluation consisted of a general clinical examination including measurement of weight, core temperature and physical examination. Core temperature was measured orally using an electronic thermometer. In very few young children it was measured rectally. Ethical clearance was provided by the local ethics committee.

\section{Drug treatment}

Patients with parasitologically proven $P$. falciparum mono infections who were not included in 5 antimalarial efficacy trials $(\mathrm{n}=2408)$ (see below) were treated with amodiaquine-artesunate and followed for approximately $2-4$ weeks. Patients who met the inclusion criteria for enrolment into drug efficacy trials $(\mathrm{n}=930)$ involving artesunate alone, mefoloquine alone, artesunate-mefloquine, artesunate-amodiaquine and artemether-lumefantrine were enrolled into these studies and have been reported elsewhere [11-16].

\section{Assessment of parasitaemia}

Thick and thin blood films prepared from a finger prick were Giemsa-stained and were examined by light microscopy under an oil-immersion objective, at $\times 1000$ magnification, by two independent assessors (microscopists). A senior member of the study team reviewed the slides if there was any disagreement between the two microscopists. In addition, one in every four blood slides was reviewed by this senior member. Parasitaemia in thick films was estimated by counting asexual parasites relative to 1000 leukocytes, or 500 asexual forms, whichever occurred first. From this figure, the parasite density was calculated assuming a leukocyte count of $6000 / \mathrm{mL}$ of blood. Gametocytes were also counted in thick blood films against 1000 leukocytes assuming an average leukocyte count of $6000 / \mathrm{mL}$ of blood [17-19]. Haematocrit was done at enrolment in 1794 children.

\section{Statistical analysis}

Data were analysed using version 6 of the Epi-Info software [20], and the statistical program SPSS for Windows version 10.01 [21]. Proportions were compared by calculating Chi square with Yates' correction. Normally distributed, continuous data were compared by Student's t-tests and analysis of variance (ANOVA). Data not conforming to a normal distribution were compared by the Mann-Whitney U-test and the Kruskal-Wallis test (or by Wilcoxon rank sum test). The association between body temperature and parasite density was assessed by Spearman's correlation coefficient. Semi-log plot of mean parasite density versus temperature, and the direct plot of log parasite density versus temperature were examined. The parasitaemia associated with an increase of $1^{\circ} \mathrm{C}$ from $37.5^{\circ} \mathrm{C}$ was determined by calculating the value between any two temperatures and the difference in parasitaemia on the semi-log plots and the non-log-transformed parasitaemias. A multiple logistic regression model was used to test the association between hypeparasitaemia (yes or no at presentation) and factors that were significant at univariate analysis: age, duration of illness before presentation, and presence of fever (temperature $>37.4^{\circ} \mathrm{C}$ ). Because the study was conducted over a period of 3 years, time in years since the commencement of study was included as a covariate in the model. P-values of $<$ 0.05 were taken to indicate significant differences.

\section{Results}

During the study period, 6807 children with illnesses suspected to be or diagnosed as malaria were evaluated. Parasitaemia was present in 3338 children, a parasite rate of $49 \%$. The clinical characteristics of the 3338 children enrolled in the study are summarized in Table 1 . Twenty eight percent of parasite-positive children were aged less than 5 years, and hyperparasitaemia occurred in 3\%. Parasitaemia > $150,000 / \mu \mathrm{l}$ was found in $8 \%$ of the children (Table 2).

\section{Relationship between body temperature, fever and parasitaemia}

There was a significant positive correlation between body temperature and parasitaemia $(\mathrm{r}=0.26, \mathrm{P}<$ $0.000001, \mathrm{n}=3175)$. There was also a significant relationship between log parasitaemia and body temperature (Figure 1) such that an increase in parasitaemia of $350,000 / \mu \mathrm{l}$ resulted in a $1^{\circ} \mathrm{C}$ increase in body temperature above $37.5^{\circ} \mathrm{C}$. 
Table 1 Characteristics of children with parasitaemia at baseline

\begin{tabular}{lc}
\hline Parameter & Value \\
\hline No. of children & 3338 \\
Female $(\%)$ & $1591(48)$ \\
Aged $<5$ years & 938 \\
Febrile $\left(>37.4^{\circ} \mathrm{C}\right)$ & 1701 \\
Hyperparasitaemic $(>250,000$ (/ $/$ l of blood) & 97 \\
Anemic $(<30 \%)$ & $461(n=1794)^{*}$ \\
$(<15 \%)$ & $8^{* *}$ \\
Mean value (range) for: & $7.4(0.16-17)$ \\
Age (year) & $21.7(5-71)$ \\
Weight (kg) & $3.2(1-21)$ \\
Duration of illness (d) & $37.7(35-41.1)$ \\
Temperature $\left({ }^{\circ} \mathrm{C}\right)$ & $32.2(10-51)$ \\
Hematocrit $(\%)$ & $9440(750-2,250,000)$ \\
GMPD $(/ \mu l$ of blood)
\end{tabular}

*24 of 70 children with hyperparasitaemia and 437 of 1724 children without hyperparasitaemia had a PCV < 30\% ( $\mathrm{P}=0.09)$.

** 1 of 70 children with hyperparasitaemia and 7 of 1724 children without hyperparasitaemia had a PCV $<15 \%(P=0.27)$.

\section{Factors associated with hyperparasitaemia at presentation}

Factors associated with hyperparasitaemia at enrolment are presented in Table 3 . An age $<11$ years, duration of illness $\leq 3 \mathrm{~d}$, presence of fever, and enrolment after year 2008 were related to the presence of hyperparasitaemia at enrolment. Neither packed cell volume at presentation nor season of presentation was related to the presence of hyperparasitaemia (Table 3).

\section{Risk factors for hyperparasitaemia at presentation}

In the multivariable analysis, an age $<11$ years, presence of fever, and enrolment after year 2008 were found to be independent risk factors for the presence of hyperparasitaemia at enrolment (Table 4).

\section{Risk for progression to other forms of severe malaria}

Eleven of 3338 children (0.3\%) progressed to cerebral malaria: 7 of these had hyperparasitaemia and 4 had no hyperparasitaemia. The difference between the two proportions was significant $(\mathrm{P}<0.0001$, by Fisher exact test). Seven of the children were $<5$ year olds. The risk of progression was considerably higher in $<5$ year olds with hyperparasitaemia ( 5 of $30 v 2$ of $67 \mathrm{P}=0.02$ ). One of the

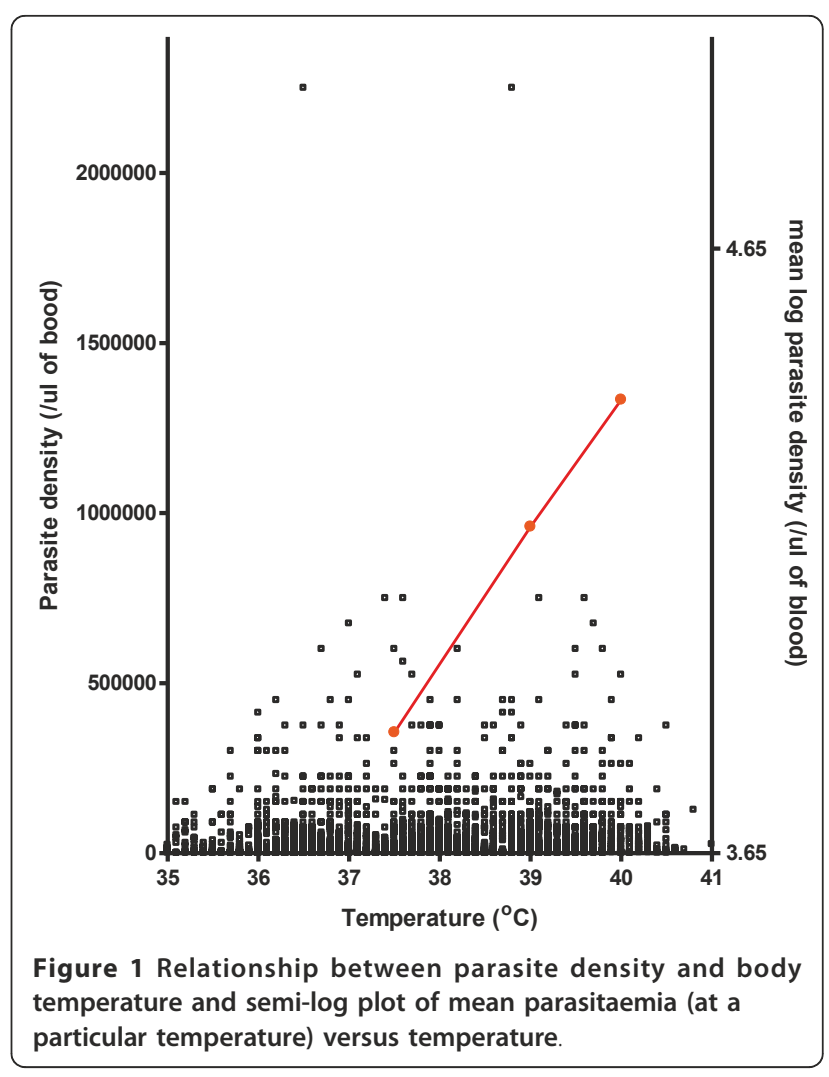

3338 children died from cerebral malaria; the child had no hyperparasitaemia at presentation.

\section{Discussion}

Although malaria is major cause of childhood morbidity and mortality in sub-Saharan Africa and hyperparasitaemia is considered a feature of severe malaria [1,2], few studies from this region have described the risk factors for hyperparasitaemia in this population. In the current study, there was clearly a broader age range for susceptibility to hyperparasitaemia-a departure from those of other forms of severe malaria in African children, for example, cerebral malaria, where children $<5$ year olds are generally more susceptible.

As was expected, duration of illness $<4$ days was associated with increased risk of hyperparasitaemia. This relatively short duration is reminiscent of the short duration of illness for other forms of severe malaria, for

Table 2 Distribution of parasitaemia in children enrolled in the study

\begin{tabular}{|c|c|c|c|c|c|}
\hline \multirow{2}{*}{$\begin{array}{l}\text { Period } \\
\text { (year) }\end{array}$} & \multirow[t]{2}{*}{ No. screened } & \multirow[t]{2}{*}{ No. positive for P. falciparum } & \multicolumn{3}{|c|}{ Parasite density $(/ \mu \mathrm{l}$ of blood) } \\
\hline & & & $>250,000$ & $>150,000-250,000$ & $<150,000$ \\
\hline 2008 & 1956 & 912 & 11 & 39 & 862 \\
\hline 2009 & 2853 & 1469 & 50 & 77 & 1342 \\
\hline 2010 & 1998 & 957 & 36 & 56 & 865 \\
\hline
\end{tabular}


Table 3 Univariable analysis of potential risk factors for hyperparasitemia in children with Plasmodium falciparum malaria

\begin{tabular}{|c|c|c|c|c|}
\hline \multirow[t]{2}{*}{ Parameter } & \multicolumn{2}{|c|}{ Number of children } & \multirow{2}{*}{$\begin{array}{c}\text { Crude OR } \\
(95 \% \mathrm{Cl})\end{array}$} & \multirow[t]{2}{*}{$P$ value } \\
\hline & Screened & HP & & \\
\hline \multicolumn{5}{|l|}{ Age (year) } \\
\hline$>11$ & 645 & 6 & 1 & 0.0001 \\
\hline$\leq 11$ & 2693 & 91 & $3.72(1.62-8.54)$ & \\
\hline \multicolumn{5}{|l|}{ Gender } \\
\hline Male & 1729 & 52 & 1 & 0.83 \\
\hline Female & 1591 & 45 & $1.06(0.71-1.59)$ & \\
\hline \multicolumn{5}{|l|}{ Duration (d) } \\
\hline$>3$ & 677 & 10 & 1 & 0.013 \\
\hline$\leq 3$ & 2406 & 78 & $2.23(1.15-4.34)$ & \\
\hline \multicolumn{5}{|l|}{ Temp $\left({ }^{\circ} \mathrm{C}\right)$} \\
\hline$<37.5$ & 1474 & 25 & 1 & 0.001 \\
\hline$\geq 37.5$ & 1701 & 63 & $2.22(1.39-3.56)$ & \\
\hline \multicolumn{5}{|l|}{ Haematocrit (\%) } \\
\hline$<30$ & 461 & 24 & 1 & 0.09 \\
\hline$\geq 30$ & 1333 & 46 & $1.53(0.92-2.54)$ & \\
\hline \multicolumn{5}{|c|}{ Year of enrolment } \\
\hline during 2008 & 912 & 11 & 1 & 0.0001 \\
\hline After 2008 & 2426 & 86 & $3.01(1.60-5.66)$ & \\
\hline \multicolumn{5}{|l|}{ Season* } \\
\hline Wet & 2540 & 79 & 1 & 0.22 \\
\hline Dry & 798 & 18 & $1.39(0.82-2.33)$ & \\
\hline
\end{tabular}

*Wet season, April to October; dry season, November to March

example, cerebral malaria where a short duration of illness is the norm [1]. However a short duration of illness was not an independent risk factor for hyperparasitaemia.

For two amongst many other reasons, it was surprising that anemia in under five year-olds, considered a surrogate marker of malaria disease burden in African children [22], was not associated with hyperparasitaemia in the cohort of children evaluated: a parasitaemia $>10,000 / \mu \mathrm{l}$ is a risk factor for malarial anaemia in children from this endemic area [23]; malaria is a major cause of anaemia in African children $[24,25]$. However, anemia was present in over $25 \%$ of cohort of children evaluated-prevalence considerably less than $39 \%$ in young children from the same endemic area [23]. The lack of association between anaemia and hyperparasitaemia may be due to the fact that anaemia may be multi-factorial in African children and the contribution of haemoglobinopathies and malnutrition to the anemia in these children may be considerable [26-28].

In a study from rural areas of Nigeria, Fasan \& Lambo (1969)[29], and Delfini (1973)[30] found that increases in body temperature were associated with increasing parasitaemia in children with malaria but the relationship between density and temperature in the individual patients was not explored. In the present study, there was a significant relationship between log parasitaemia and body temperature such that an increase in parasitaemia of $350,000 / \mu \mathrm{l}$ resulted in a $1^{\circ} \mathrm{C}$ increase in body temperature above $37.5^{\circ} \mathrm{C}$. This represents a substantial increase in asexual parasitaemia per unit rise in body temperature in this cohort of children. Additionally, fever was an independent risk factor for hyperparasitaemia. Indeed, children with fever were twice as likely to have a hyperparasitaemia compared to children without fever. This relationship and the associated risk may have been partially attenuated by the prior administration of antipyretic agents before presentation because approximately $68 \%$ of parents or guardians in this endemic area would give the antipyretic, acetaminophen, to their children at some point during a febrile illness before consultation (Sowunmi, unpublished).

Table 4 Multivariable analysis of independent risk factors for hyperparasitaemia in children with Plasmodium falciparum malaria

\begin{tabular}{|c|c|c|c|c|c|c|}
\hline Parameter & Total No. & No. with HP & $\begin{array}{c}\text { Crude OR } \\
(95 \% \mathrm{Cl})\end{array}$ & $P$ value & $\begin{array}{c}\text { Adjusted OR } \\
(95 \% \mathrm{Cl})\end{array}$ & $P$ value \\
\hline \multicolumn{7}{|l|}{ Age (year) } \\
\hline$>11$ & 645 & 6 & 1 & 0.0001 & 1 & 0.014 \\
\hline$\leq 11$ & 2693 & 91 & $3.72(1.62-8.54)$ & & $2.85(1.23-6.61)$ & \\
\hline \multicolumn{7}{|l|}{ Duration (d) } \\
\hline$>3$ & 677 & 10 & 1 & 0.013 & 1 & 0.07 \\
\hline$\leq 3$ & 2406 & 78 & $2.23(1.15-4.34)$ & & $1.85(0.94-3.63)$ & \\
\hline \multicolumn{7}{|l|}{ Temp $\left({ }^{\circ} \mathrm{C}\right)$} \\
\hline$<37.5$ & 1474 & 25 & 1 & 0.001 & 1 & 0.005 \\
\hline$\geq 37.5$ & 1701 & 63 & $2.22(1.39-3.56)$ & & $2.02(1.23-3.29)$ & \\
\hline \multicolumn{7}{|c|}{ Year of enrolment } \\
\hline during 2008 & 912 & 11 & 1 & 0.0001 & 1 & 0.001 \\
\hline After 2008 & 2426 & 86 & $3.01(1.60-5.66)$ & & $3.07(1.57-5.99)$ & \\
\hline
\end{tabular}

$\mathrm{HP}$, hyperparasitaemia (asexual parasites $>250,000 / \mu \mathrm{l}$ of blood) 
In contradistinction to the finding in an area of lesser intensity of transmission, for example, on the ThaiBurmese border, where hyperparasitaemia is associated with the dry season [31], there was no association between season and the risk of hyperparasitaemia in this area of intense transmission. The reasons for the lack of association in the present study are unclear but more studies are required. It is also intriguing that enrolment after 2008 was an independent risk factor for hyperparasitaemia. There is, as yet, no ready explanation for this observation.

All the possible risk factors for hyperparasitaemia were not captured in the present study. Recent histories of diarrhoea and the presence of gametocytes, a finding associated with hyperparasitaemia in Thailand [9], for examples, were not considered. Nevertheless, a large number of children were evaluated. Hyperparasitaemia was associated with increased risk of progression to cerebral malaria suggesting that hyperparasitaemia should not be considered as variabe depending on epidemiology setting in childhood malaria as was done in the original WHO document [1] but be retained as a component of severe malaria at all times in children $<5$ years. Thus, the results described in this study population should have significance in shaping the diagnosis of and guidelines for the management of hyperparasitaemia in children in African setting.

\section{Conclusion}

In conclusion, a relatively broader age range, fever and enrolment after year 2008 are independent risk factors for hyperparasitaemia in malarious children in this endemic area. Hyperparasitaemia is significantly associated with an increased risk of progression to cerebral malaria in young children $<5$ years old.

\section{Acknowledgements}

We thank Dr. S.O. Michel and Ebunsola Oyetade for assisting with the conduct of the study.

\section{Authors' contributions}

AS led the design, conduct, data analysis and manuscript preparation, TMO was involved in conduct, data analysis and manuscript preparation, GOG and $\mathrm{CTH}$ were involved in design, conduct and preparation of the manuscript. All authors read and approved the final version of the manuscript.

\section{Conflicts of interests}

The authors declare that they have no competing interests.

Received: 15 March 2011 Accepted: 9 October 2011

Published: 9 October 2011

\section{References}

1. World Health Organization: Severe and complicated malaria. Trans $R$ Soc Trop Med Hyg 1990, 84(Suppl 2):1-65.

2. World Health Organization: Severe falciparum malaria. Trans $R$ Soc Trop Med Hyg 2000, 94(Suppl 1):1-90.

3. White NJ, Pontavornpinyo W, Maude RJ, Saralamba S, Aguas R, Stepniewska K, Lee SJ, Dundorp AM, White LJ, Day NPJ: Hyperparasitaemia and low dosing are an important source of anti-malarial drug resistance. Malarial J 2009, 8:253.

4. Stepniewska K, Ashley E, Lee SJ, Anstey N, Barnes KI, Binh TQ, D'Alessandro U, Day NPJ, de Vries PJ, Dorsey G, Guthmann J-P, Mayxay M, Newton PN, Olliaro P, Osorio L, Price RN, Rowland M, Smithuis F, Taylor WRJ, Nosten F, White NJ: In vivo parasitological measures of artemisinin susceptibility. J Infect Dis 2010, 201:570-579.

5. Sowunmi A, Walker O, Salako LA: Hyperparasiteamia: not a reliable indicator of severity or poor prognosis in falciparum malaria in children in endemic African countries. Ann Trop Paediatr 1992, 12:155-158.

6. Tripathi R, Parida S, Das L, Mishra DP, Tripathi D, Das MC, Chen H, Maguire JH, Panigrahi P: Clinical manifestations and predictors of severe malaria in Indian children. Pediatrics 2007, 120:e454-60.

7. Sowunmi A, Adewoye EO, Gbotosho GO, Happi CT, Sijuade AO, Folarin OA, Okuboyejo TM, Michael OS: Factors contributing to delay in parasite clearance in uncomplicated falciparum malaria in children. Malaria $J$ 2010, 9:53

8. Dorsey G, Gasasira AF, Machekano R, Kamya MR, Staedke SG, Hubbard A: The impact of age, temperature, and parasite density on treatment outcomes from antimalarial trials in Kampala, Uganda. Am J Trop Med Hyg 2004, 71:531-536.

9. Nacher M, Singhasivanon P, Silachamroon U, Treeprasertsuk S, Tosukhowong T, Vannaphan S, Gay F, Mazier D, Looareesuwan S: Decreased hemoglobin concentrations, hyperparasitemia and severe malaria are associated with increased Plasmodium falciarum gametocyte carriage. J Parasitol 2002, 88:97-101.

10. Salako LA, Ajayi FO, Sowunmi A, Walker O: Malaria in Nigeria: a revisit. Ann Trop Med Parasitol 1990, 84:435-445.

11. Sowunmi A, Gbotosho GO, Happi CT, Adedeji AA, Fehintola FA, Folarin OA, Tambo E, Fateye BA: Therapeutic efficacy and effects of artemetherlumefantrine and amodiaquine-sulfalene-pyrimethamine on gametocyte carriage in children with uncomplicated Plasmodium falciparum malaria in southwestern Nigeria. Am J Trop Med Hyg 2007, 77:235-241.

12. Sowunmi A, Balogun $T$, Gbotosho GO, Happi CT, Adedeji AA, Fehintola FA: Activities of amodiaquine, artesunate, and artesunate-amodiaquine against asexual- and sexual-stage parasites in falciparum malaria in children. Antimicrob Agents Chemother 2007, 51:1694-1699.

13. Sowunmi A, Gbotosho GO, Happi C, Okuboyejo T, Folarin O, Balogun S, Michael O: Therapeutic efficacy and effects of artesunate-mefloquine and mefloquine alone on malaria-associated anemia in children with uncomplicated Plasmodium falciparum malaria in southwest Nigeria. Am J Trop Med Hyg 2009, 81:979-986.

14. Michael OS, Gbotosho GO, Folarin OA, Okuboyejo T, Sowunmi A, Oduola AMJ, Happi CT: Early variation in Plasmodium falciparum dynamics in Nigerian children after treatment with two artemisininbased combinations: implications on delayed parasite clearance. Malaria J 2010, 9:335.

15. Gbotosho GO, Sowunmi A, Okuboyejo TM, Happi CT, Folarin OO, Michael SO, Adewoye EO: Therapeutic efficacy and effects of artemetherlumefantrine and artesunate-amodiaquine co-formulated or copackaged, on malaria-associated anemia in children with uncomplicated Plasmodium falciparum malaria in southwest Nigeria. Am J Trop Med Hyg 2011, 84:813-819.

16. Gbotosho GO, Sowunmi A, Happi C, Okuboyejo T: Therapeutic efficacies of artemisinin-based combination therapies in Nigerian children with uncomplicated falciparum malaria during five years of adoption as firstline treatments. Am J Trop Med Hyg 2011, 84:936-943.

17. Shaper $A G$, Lewis P: Genetic neutropenia in people of African origin. Lancet 1971, ii:1021-1023.

18. Ezeilo GC: Neutropenia in Africans. Trop Geog Med 1971, 23:264-267.

19. Sowunmi A, Akindele JA, Balogun MA: Leukocyte counts in falciparum malaria in African children from an endemic area. Afr J Med Med Sci 1995, 24:145-149.

20. Epi Info Version 6: A Word Processing Data Base and Statistics Program for Public Health on IBM-compatible Microcomputers. Centers for Disease Control and Prevention, Atlanta, GA; 1994.

21. SPSS for Windows Release 10.01 (standard version). SPSS Inc., Chicago, IL; 1999.

22. Korenromp EL, Armstrong-Schellenberg JR, Williams BG, Nahlen BL, Snow RW: Impact of malaria control on childhood anaemia in Africa. Trop Med Inter Health 2004, 9:1050-1065. 
23. Sowunmi A, Gbotosho GO, Happi $C T$, Fateye BA: Factors contributing to anaemia after uncomplicated Plasmodium falciparum malaria in children. Acta Tropica 2009, 113:155-161.

24. Hedberg K, Shaffer N, Davachi F, Hightower A, Lyamba B, Paluku KM, Nguyen Dinh P, Breman JG: Plasmodium falciparum-associated anemia in children at a large urban hospital in Zaire. Am J Trop Med Hyg 1993, 48:365-371.

25. Crawley J: Reducing the burden of anemia in infants and young children in malaria-endemic countries of Africa. Am J Trop Med Hyg 2004, 71(Suppl 2):25-34.

26. Fleming AF, Storey J, Molineaux L, Iroko EA, Attai ED: Abnormal haemoglobins in the Sudan savanna of Nigeria. I. Prevalence of haemoglobins and relationships between sickle cell trait, malaria and survival. Ann Trop Med Parasitol 1979, 73:161-172.

27. Mockenhaupt FP, Falusi AG, May J, Ademowo OG, Olumese PE, Meyer CG, Bienzle $\mathrm{U}$ : The contribution of $\mathrm{a}^{+}$thalassaemia to anaemia in a Nigerian population exposed to intense malaria transmission. Ann Trop Med Inter Health 1999, 4:302-307.

28. Ehrhardt S, Burchard GD, Mantel C, Cramer JP, Kaiser S, Kubo M, Otchwemah RN, Bienzle U, Mockenhaupt FP: Malaria, anemia, and malnutrition in African children-defining interventional priorities. J Infect Dis 2006, 94:108-114.

29. Fasan PO, Lambo AO: Malaria parasitaemia and body temperature in a semi-immune population in southern Nigeria. Bull World Health Org 1969, 41:309-311.

30. Delfini LF: The relationship between body temperature and malaria parasitaemia in rural forest areas of western Nigeria. J Trop Med Hyg 1973, 73:111-114.

31. Nacher M, Carrara VI, Ashley E, McGready R, Hutagalung R, Nguyen JV, Thwai KL, Looareesuwan S, Nosten F: Seasonal variation in hyperparasitaemia and gametocyte carriage in patients with Plasmodium falciarum malaria on the Thai-Burmese border. Trans R Soc Trop Med Hyg 2004, 98:322-328.

\section{Pre-publication history}

The pre-publication history for this paper can be accessed here: http://www.biomedcentral.com/1471-2334/11/268/prepub

doi:10.1186/1471-2334-11-268

Cite this article as: Sowunmi et al:: Risk factors for Plasmodium falciparum hyperparasitaemia in malarious children. BMC Infectious Diseases 2011 11:268.

\section{Submit your next manuscript to BioMed Central and take full advantage of:}

- Convenient online submission

- Thorough peer review

- No space constraints or color figure charges

- Immediate publication on acceptance

- Inclusion in PubMed, CAS, Scopus and Google Scholar

- Research which is freely available for redistribution

Submit your manuscript at www.biomedcentral.com/submit 